\title{
The MASON HouseholdsWorld Model of Pastoral Nomad Societies
}

\author{
Claudio Cioffi-Revilla ${ }^{1}$, J. Daniel Rogers ${ }^{2}$, and Maciek Latek ${ }^{1}$ \\ ${ }^{1}$ Center for Social Complexity and Department of Computational Social Science, MSN 6B2 \\ Krasnow Institute for Advanced Study, George Mason University, 4400 University Drive, \\ Fairfax, VA 22030 USA \\ \{ccioffi,mlatek\}@gmu.edu \\ ${ }^{2}$ Department of Anthropology, NHB 112 \\ National Museum of Natural History, 10th and Constitution Avenue, \\ Washington, DC 22013 USA \\ rogersd@si.edu
}

\begin{abstract}
Computational modeling of pastoralist societies that range as nomads over diverse environmental zones poses interesting challenges beyond those posed by sedentary societies. We present HouseholdsWorld, a new agentbased model of agro-pastoralists in a natural habitat that includes deserts, grasslands, and mountains. This is the paper-of-record for the HouseholdsWorld model as part of a broader interdisciplinary project on computational modeling of long-term human adaptations in Inner Asia. The model is used for conducting experiments on socio-environmental interactions, social dynamics experiments, and for developing additional models with higher levels of social complexity.
\end{abstract}

Keywords: Social simulation, agent-based modeling, computational social science, pastoral, nomads, Inner Asia, Mongolia, MASON toolkit, coupled socio-natural systems, climate change, social complexity.

\section{Introduction: Motivation and Background}

From a comparative social perspective, nomadic societies-Mongols, Huns, Roma, Beduins, among others - exhibit a defining or characteristic form of collective spatial mobility that distinguishes them from the much larger class of sedentary societies. While the drivers of nomadism can differ across societies, as well as through time, a common cause of spatial displacement arguably involves the need to follow herds of animals or other valued resources. In turn, and crucially, herds follow the changing environment according to a yearly cycle and other longer-term weather or climate 
patterns. Annual seasons determine local migrations; decadal or longer climate cycles can also determine inter-regional or other long-distance migrations. The number of natural habitats or ecosystems traversed by a nomadic group may be taken as a measure of its mobility, in addition to physical distance.

In Inner Asia and the Eurasian steppe, pastoral nomadic societies have played an influential role in shaping world history, at least since the rise of the Xiong-nu (Hünnü) during the late 3rd century and early 2nd century BCE, in the Ordos region and far beyond. ${ }^{1}$ As described in the Chinese classic Shih chi (Shiji) by the Han court scribe Ssu-ma Ch'ien:

Each group had its own area, within which it moves about from place to place looking for water and pasture (Watson, 1961: 163-164).

Interestingly, nomadism also has effects on political organization and forms of governance, given the challenges and opportunities posed by collective mobility. As a result, nomadic societies have evolved their own adapted versions of chiefdoms, states, and empires (Rogers, 2007). The spatial mobility of institutions is a common necessity in nomadic societies, whereas it is rare for sedentary societies (e.g., moving a capital city or administrative center). Nomadic households are the fundamental and simplest building blocks at the bottom of the hierarchy of human groups that constitute a polity and its governance institutions. In turn, households belong to clans and tribes, which-in Inner Asia and other world regions populated by pastoral nomadic societies - in turn form confederations and other higher-level polities. Membership in such supra-household social groupings (e.g., clans, tribes, sects, and other communities) is key to understanding social organization and dynamics, including patterns of war and peace.

Social simulations of nomadic and pastoralist societies provide unique computational models and virtual laboratories for testing generative theories (Epstein, 2007) of social complexity among interactive and mobile agents, as well as for exploring and discovering new patterns of socio-environmental interactions (Kohler, 2007). In addition, the possibility of conducting in silico experiments is especially valuable, because household interaction and mobility often raise a number of "what if" questions associated with contingencies of time and space (e.g., the rise of the Mongol empire in the 13th century, not earlier in history or elsewhere in Asia). Theoretical development, discovery, and experimentation provide the basic motivation for the model described in this paper.

Simulation models of nomadic pastoralist societies include agent-based models of target systems ranging from regions in Africa (see, e.g., Rouchier et al., 2001; Kuznar and Sedlmeyer, 2005; Bah et al., 2006) to the Arctic regions (Berman et al., 2004),

\footnotetext{
${ }^{1}$ The influence of pastoral nomadic societies from the steppes of Eurasia on world history antedates the Xiong-nu period and the opening of the Silk Roads, as far back as 1000 BCE and the Scythians: "The Scythians and the related Sarmatians are the first steppe nomads of whom we have any real knowledge, although the Romans had long contact with the Parthians, another related people who came off the steppe to found an empire in what had been Persian territory" (Hildinger, 1997: 33). See also Grousset (1970: ch.1) and Christian (1998: chs. 6-8) for general histories of this formative period in the rise of Asian steppe pastoral nomad societies.
} 
the MASON Wetlands model (Cioffi-Revilla et al., 2004b), and a model of contemporary pastoralist behavior in Kazakhstan (Milner-Gulland, 2006). The model described in this paper builds on selected features of earlier models, by adding arguably more explicit social attributes and dynamics, and is also part of a larger interdisciplinary collaborative project aimed at investigating long-term adaptation and sociopolitical change in Inner Asia (Cioffi-Revilla et al., 2007; Cioffi-Revilla, 2008; Rogers and Cioffi, forthcoming).

The emergence of sociopolitical complexity is a research question that models in our project seek to address. A new model was necessary because earlier models addressed different questions (e.g, sustainability, role of memory, or ethnic conflict). Specifically, the primary purpose of the HouseholdsWorld model is to gain a better understanding of pastoral nomadic dynamics-among households and between households and natural environments-including human and societal adaptive behavior to long-term change. For example, the HouseholdsWorld model is capable of answering research questions concerning societal consequences of climate change and other environmental challenges to human societies (Rogers, Latek, and Altman, 2009). The second purpose is to provide a basis or building block for modeling a larger and more complex target system, including the emergence of political organization (Cioffi-Revilla et al., 2008). This is the paper-of-record for the MASON HouseholdsWorld Model version 1 (or HouseholdsWorld, for short).

\section{The HouseholdsWorld Model}

By way of context, the MASON HouseholdsWorld model is the initial social simulation model in a progression of models aimed at simulating the rise and fall of polities in Inner Asia over a long time span (Cioffi-Revilla et al., 2007). The time is defined as sufficiently long to include significant climate change. When climate changes, the biomass distribution on the landscape changes, which in turn leads to changes in the biological and social dynamics of animals and people, respectively.

HouseholdsWorld is a spatial agent-based model of pastoral nomads living in a simple socio-natural system, as shown by the UML class diagram in Figure 1 . The main agent classes are Household and Camp, where the former also belong to a Clan. The model is written in the MASON system (Luke et al., 2005) in order to exploit a set of project-specific features, such as platform independence in Java, guaranteed replicability, separation of computation from visualization, and evolutionary computation facilities which we plan to use in the future. Separate social, environmental, dynamic, and implementation aspects of the model are described next.

The target system is a generic locality smaller than a region of Inner Asia shortly after ca. $500 \mathrm{BCE}$, the time period just prior to the rise of the Xiung-nu polity (ca. 200 BCE). The primary sources used for developing the HouseholdsWorld model were epigraphic (e.g., Watson, 1961), archaeological, ethnographic, and environmental, as detailed in the subsections below. Secondary historical sources (e.g., Christian, 1998; Grousset, 1970; Hildinger, 1997; and others), as well as area experts (see below), where also consulted. 


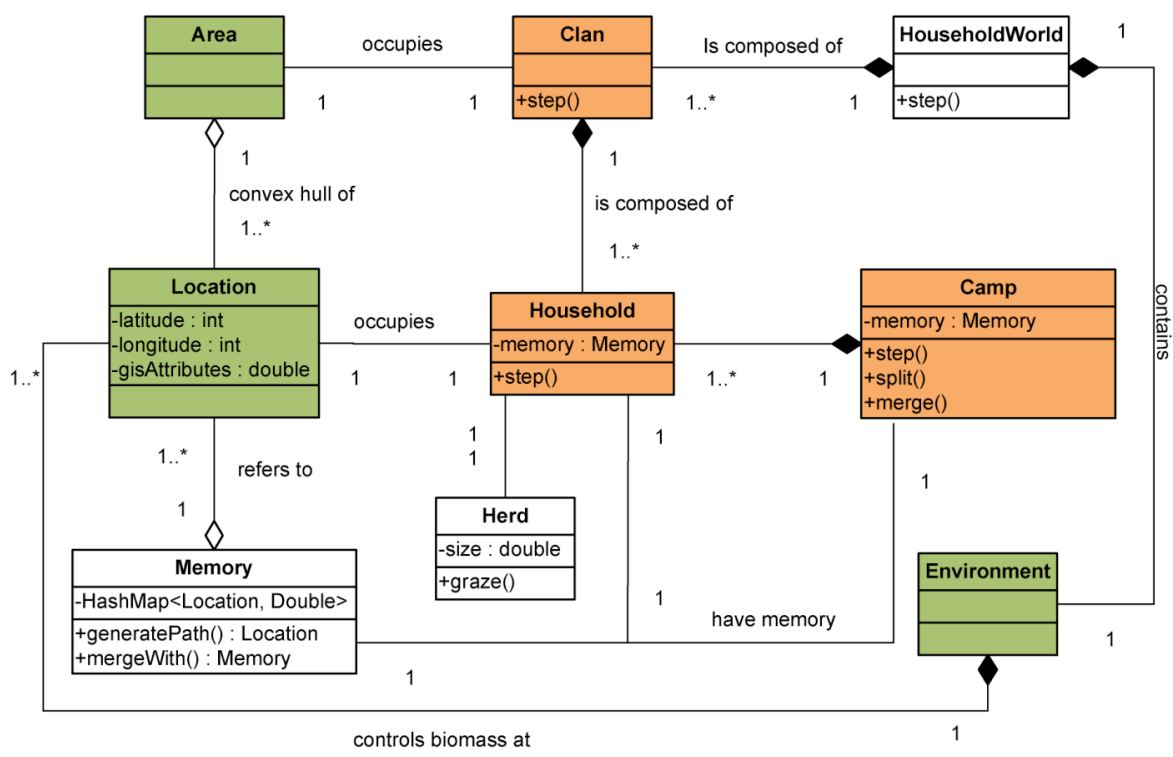

Fig. 1. High-level UML class diagram of the main components and relations in the HouseholdsWorld model, including the main attributes of Households and Camps. Agent classes (orange) and spatial classes (green) inherit from the MASON Steppable interface and from a subset of Geotools GIS attributes (describe areas, location), respectively.

\subsection{Households}

Households are the smallest social units in the model. For our purposes, we do not specify individual persons, but rather focus on households - extended families-and their behavior around herds of animals. Each household needs to ensure sufficient forage for its herd (a herd multiplies if enough forage is available, otherwise it starts dying at a predetermined rate), as detailed by the main simulation loop illustrated in Figure 2.

The movement rules mentioned in Figure 2 are defined as follows. Each movement rule $r \in S$ takes as input a cell of the environment, $c \in N$, and returns a real number,

$$
r: N \rightarrow \Re .
$$

The following five rules are currently used: ${ }^{2}$

${ }^{2}$ We are grateful to W. Honeychurch, W. Fitzhugh, B. Frohlich, and D. Tseveendorj for their expert advice on formulating these rules, based on the anthropological archaeological record of early Inner Asia and the ethnography reported for modern Mongolia. 
1. Search for forage (local): Returns grass availability for an input cell. This is the primary rule for modeling household subsistence.

2. Search for forage (global): Returns the reciprocal of distance from an input cell to the best grazing area, for a given time present in camp memory, using memorized abundance values of grazing for a given season of the year.

3. Maintain camp cohesion: Returns the reciprocal of the sum of Hamiltonian distances (defined as the minimal-length paths between cells) to camp members from an input cell.

4. Avoid other camp members and 5. Avoid other clan members: These return the sum of Hamiltonian distances from an input cell to all aliens (different clan/camp) present within a given Hamiltonian radius.

This rule set is defined at the level of households. The next section discusses the camp-level rule set.

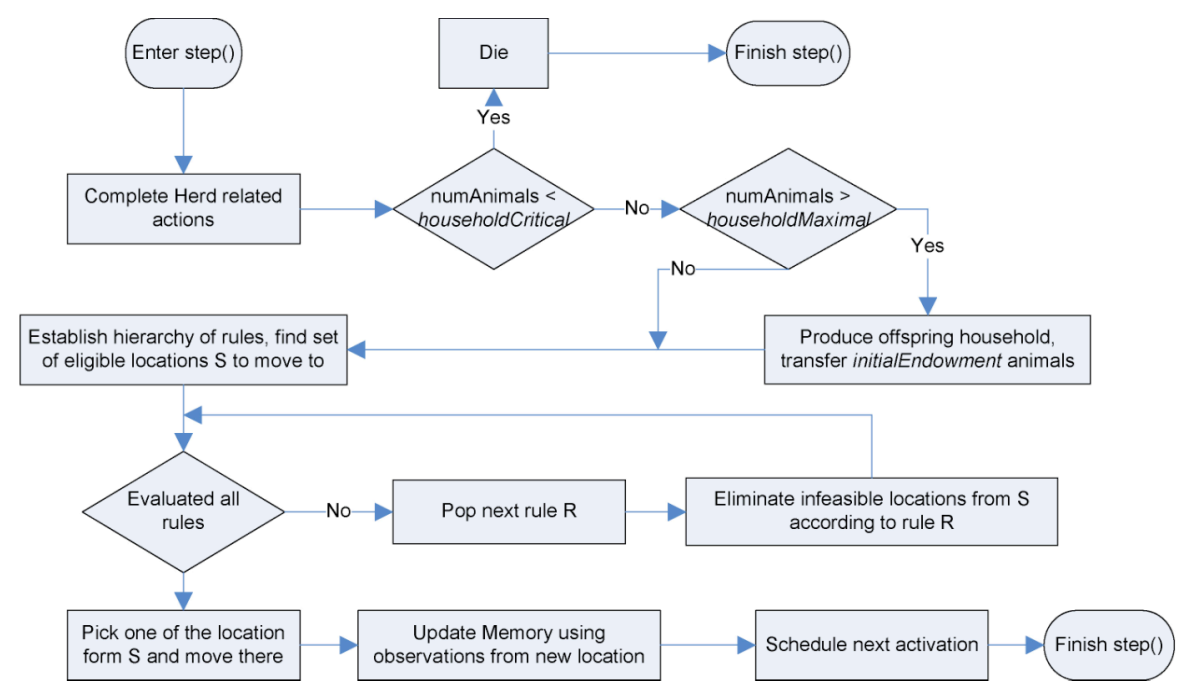

Fig. 2. Main simulation loop for HouseholdsWold agents: Flowchart detailing the process that takes place in the step method of the Household class. The loop starts at the upper left and ends at the bottom right.

The algorithm below shows how, given an ordered set of movement rules, agents decide where to move next. Note that Rule 2 requires endowing each household with grazing memory, which holds information on the best grazing areas for a given month of the year. This is a somewhat more sophisticated cognitive feature relative to our earlier Wetlands model where the hunter-gatherer agents followed a simpler rule set in a single ecological region (Cioffi-Revilla et al., 2004b). 
Algorithm for evaluation of hierarchies of movement rules.

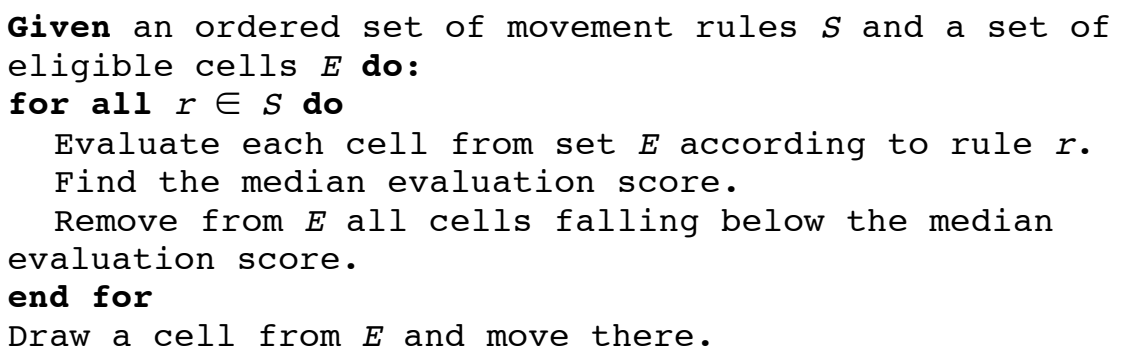

While the social ontology of the HouseholdsWold model does not include elaborate treatment of "the mind of agents" (e.g., in terms of specifically modeling desires, beliefs, and intentions (DBI), or other mental constructs and cognitive processes), the model does include some cognitive and socio-psychological elements, such as agent memory (for both households and camps), decision-making by households (for example, deciding if and where to move next), instincts (with regards to food and aliens), basic norms (ascriptive xenophobia and attraction, determined by clan membership), and intentional behaviors (motivated by needs). These elements also correspond to significant features that are known to be present in the target system-i.e., the human communities in Inner Asia after ca. 500 BCE. Note also that, while rules 1 and 2 pertain to socio-natural interactions, rules 3, 4, and 5 are about interactions among households, consistent with a complex adaptive systems approach to the human ecology of small groups (Arrow et al., 2000). ${ }^{3}$

\subsection{Camps}

Camps are composed of households, as shown earlier in Figure 1, and they follow a separate set of behavioral rules:

1. Division: If households in a camp lack sufficient forage, the camp may divide into two new camps of approximately equal size. Division occurs along either north-south or east-west directions, with new camps drifting in opposite directions.

2. Merging: If two camps meet, each with enough supplies, they merge forming a new camp. ${ }^{4}$

${ }^{3}$ In the target system, the clan or tribal membership of households is far more consequential. For example, such associations can regulate patterns of conflict by segmentary or complementary opposition, a social feature we investigate in a different albeit related model in this project (Cioffi-Revilla et al., 2008\}. In the HouseholdWold model the clan or tribal membership of households only affects their camping behavior.

${ }^{4}$.In the target system the range of camp size is 5-8 households, with larger or smaller camps increasingly infrequent (improbable). 
Iterative application of these rules yields the effect of seasonal variability in the number of camps. Thus, in winter we observe multiple small camps, while in summer camps tend to conglomerate. In addition to behavioral rules, households belonging to a single camp share information on grazing areas.

Importantly, camp behavior rules aim to reflect comparable rules in the target system of Inner Asia's pastoralist communities, similar to the motivation for household rules.

\subsection{Natural environment}

The seasonal and spatial variability of the environment of Inner Asia, centered on Mongolia, is modeled by using two data layers:

1. Monthly NDVI (normalized difference vegetation index) rasters, from atmosphere corrected bands with a 500 meter resolution; and

2. Land cover type (14 types used), originally in $1 \mathrm{~km}$ resolution.

To obtain carrying capacities from raw NDVI data, information gathered in situ by Kawamura (2004) was used to translate NDVI into the amount of biomass fit for grazing (expressed in $\mathrm{kg} / \mathrm{ha}$ ). Parameter values are shown in Table 1 . In all, the natural environment in the model consists of threes biomes-desert, grasslands (mostly), and forests - representing a significant portion of the habitat occupied by the pastoral nomads of Inner Asia.

Table 1. Main parameters of the MASON HouseholdsWorld model.

\begin{tabular}{|c|c|c|}
\hline Parameter & Value & Meaning \\
\hline householdMaximal & 40 & $\begin{array}{l}\text { Maximal number of animals a } \\
\text { household can support (if more, } \\
\text { offspring will be produced). }\end{array}$ \\
\hline householdCritical & 5 & $\begin{array}{l}\text { Minimal number of animals } \\
\text { required for the survival of a } \\
\text { household. }\end{array}$ \\
\hline householdVisionRange & 3 & Vision range for a household. \\
\hline InitialAnimalEndowment & 20 & $\begin{array}{l}\text { Number of animals that will be } \\
\text { transfered to an offspring } \\
\text { household. }\end{array}$ \\
\hline initialNumberHouseholds & 100 & $\begin{array}{l}\text { Initial number of households set } \\
\text { to a default value of } 100 \text {. }\end{array}$ \\
\hline biomassRegrowthRate & $1.5 \%$ & $\begin{array}{l}\text { How fast does the biomass grow } \\
\text { to levels for a given month per } \\
\text { day. }\end{array}$ \\
\hline
\end{tabular}




\section{Simulated Dynamics}

Like other models in MASON, HouseholdsWorld offers numerous data collection facilities, including social network and spatial clustering statistics, as well as an easyto-use GUI for demonstrating experiments. (In this paper we omit MASON facilities relevant for evolutionary computation or related tools such as ECJ; see Luke et al., 2009.) Figure 3 presents six selected outputs produced during each run of HouseholdsWorld. The model GUI displays a bird's eye view of a region where nomadic households form camps (clusters of red, blue, and yellow dots, representing three clans in panel (a)), as well as a variety of metrics (time series, histograms, and other charts not shown here for reasons of space) that track the evolution of social and/or environmental dynamics within the overall socio-natural system.

Several of the patterns produced by simulation bear significant qualitative and quantitative resemblance to comparable patterns in the target system. For example, the distribution of wealth in Figure 3(f) has the approximate form of a log-normal distribution, as a real-world distribution of household wealth usually should. Similarly, household movements in Figure 3(d) show marked periodic fluctuations, as in the real world when nomads undergo seasonal travel following their herds. While the model does not attempt to produce a specific historical or empirically replicated replication (such as, for example, migrations and settlement patterns in the wellknown Anasazi model), the overall qualitative and quantitative behavior of households, herds, and seasons are supported by known features of the target system.

The MASON system of the HouseholdsWorld model also allows for easy design of multi-run experiments, as should be with a viable virtual lab (agent-based model). Accordingly, we have used the multi-run experimental capability to search for robust grazing strategies by households. For example, we have investigated performance across different permutations of the movement rule set.

Figure 4 presents results of an exhaustive search of the space of behavioral ruleset permutations to obtain the trade-off between the maximal long-term population and the long-term variability of the population. The Pareto frontier in this case is the set of solutions that can sustain the largest population within the larger set (i.e., as a subset) of all solutions that have comparable or larger risk measures (starvation probability). It can be observed that for populations less than 3,000 , the tradeoff between risk and efficiency is small (population can increase with little punishment). However, the tradeoff changes dramatically for larger populations. For Mongolia, Krader (1955) provides observed population densities of 0.9 persons $/ \mathrm{km}^{2}$ and herd densities of 8 animals $/ \mathrm{km}^{2}$. For the particular landscape used in our simulation, the critical density is in the 3,000-5,000 households range on a $10,000 \mathrm{~km}^{2}$ landscape (corresponding to a population density of $0.3-0.5$ households $/ \mathrm{km}^{2}$ and a herd density of approximately 12-20 animals $/ \mathrm{km}^{2}$ ). Empirically observed values are some $50 \%$ lower than critical values predicted by the HouseholdsWorld model. We hope to reduce this discrepancy by introducing a data-driven model of paleo-climate, thereby increasing the environmental uncertainty faced by Inner Asian households in the real world. 


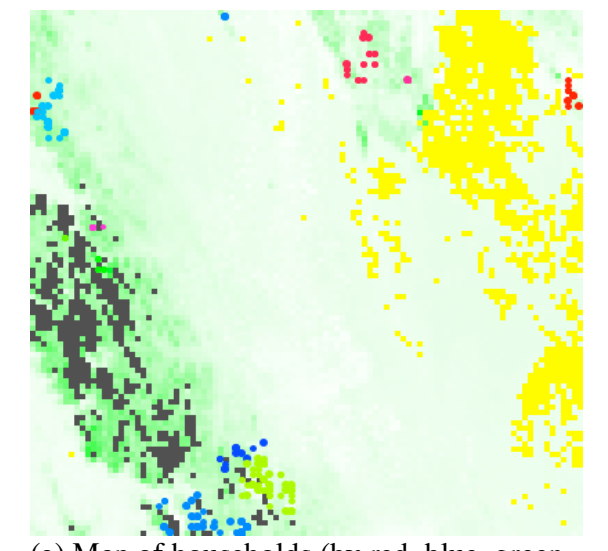

(a) Map of households (by red, blue, green clans) and landscape.

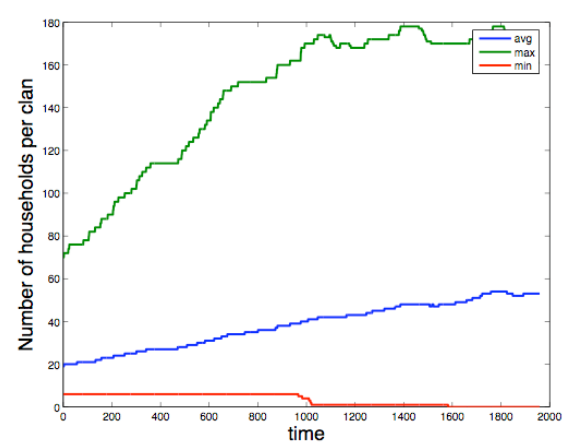

(c) Households per clan over time. Legend as in (b).

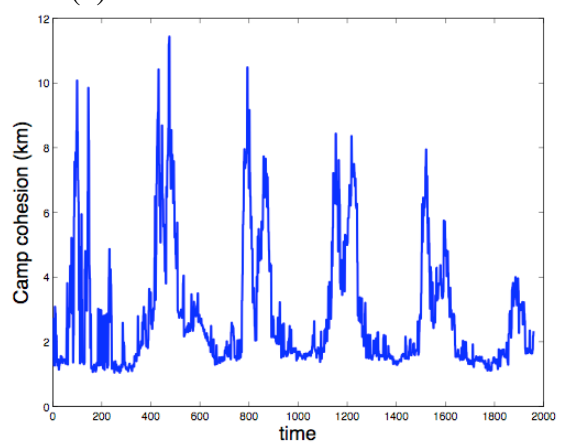

(e) Cohesion (spatial aggregation) of camps over time.

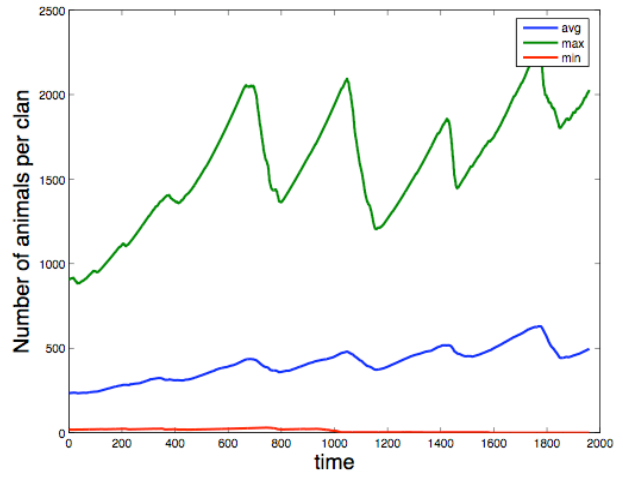

(b) Number of animals per clan over time. Blue $=$ average, Green $=$ maximum, Red $=$ minimum .

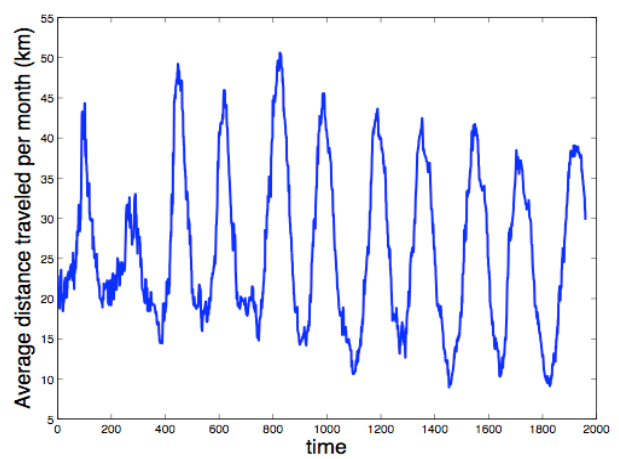

(d) Average distance/month traveled by households.

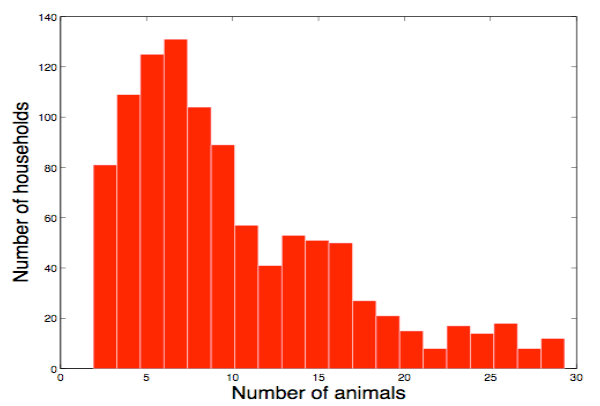

(f) Simulated distribution of household wealth approximating a log-normal distribution.

Fig. 3. Examples of simulated outputs and statistics from a single run of the HouseholdsWorld model in default landscape of $100 \times 100 \mathrm{~km}$ during summer. Timescales are expressed in days, with 300 simulated days per simulated year and approximately six years in each run. Green= biomass density, Yellow $=$ desert, Black $=$ forest. 


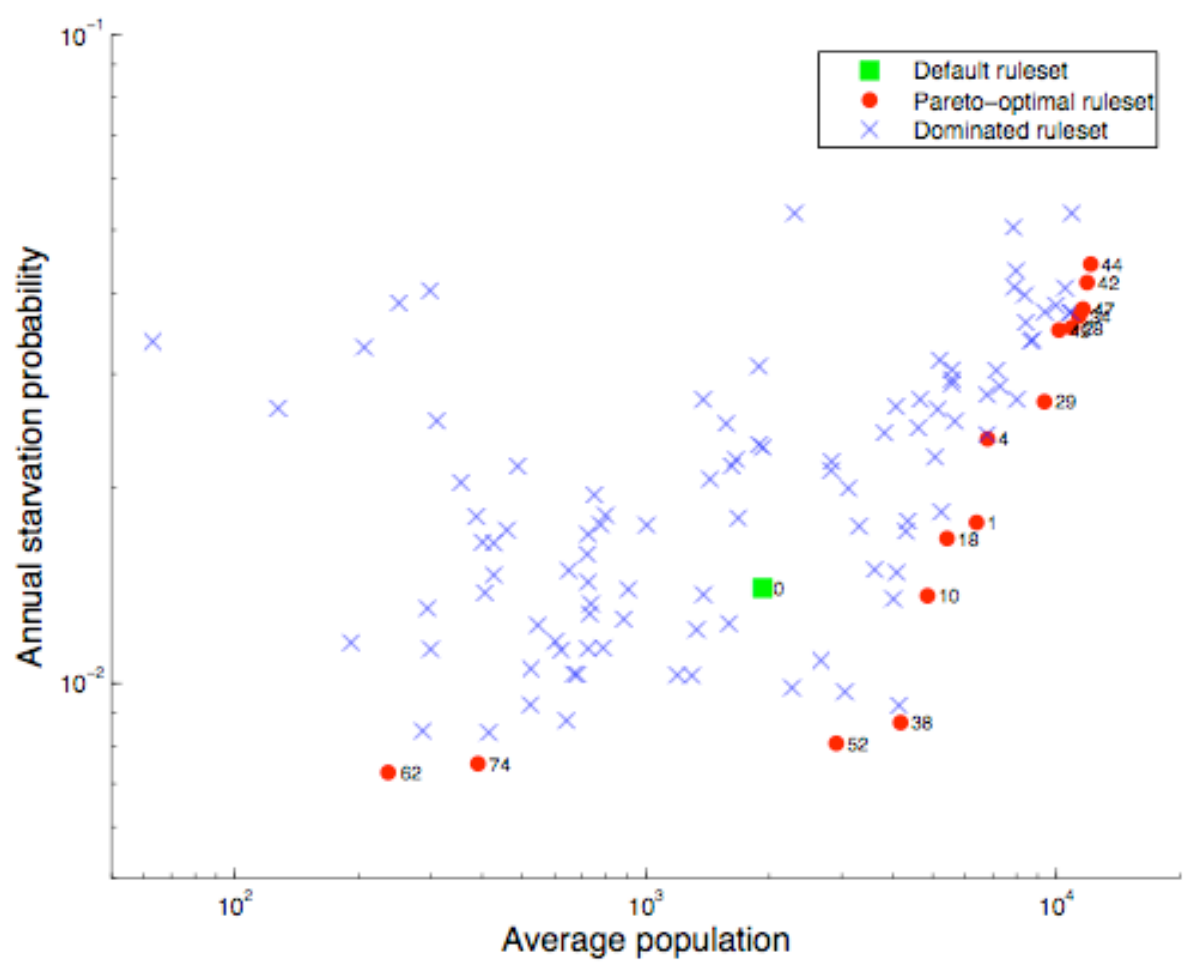

Fig. 4. Pareto frontier of permutations of the household behavioral rule-set in an average long term population plotted against starvation risk space. Note that the axes are in log-log scales. Each point represents the performance of the population following one of 120 (or 5!) possible orderings of rule sets. The permutation numbers from the graph correspond to lexicographic orderings of the default (0) rule set listed in Section 2.1. Legend: Red = points belonging to the Pareto-optimal rule-set frontier; Blue $=$ dominated rule sets; Green $=$ default rule set.

\section{Summary}

Computational modeling of nomadic pastoralist societies that range over diverse natural environments poses interesting challenges, because household mobility affects the fabric of social relations (interactions among households) as well as socionatural interactions. In this chapter we have presented the MASON HouseholdsWorld, a new agent-based model of migratory pastoralist societies in a natural habitat consisting of several biomes (grasslands, forests, deserts). Agent-based models of pastoral nomadic societies are still relatively rare in the literature, although the role of these polities in world history has been significant (Christian,1998; Grousset, 1970; Khazanov, 2004; Rogers, 2007). The MASON HouseholdsWorld model is part of a broader collaborative interdisciplinary project involving social 
scientists, computer scientists, and environmental scientists, focused on computational modeling of long-term human adaptations in Inner Asia-a vast area of the world where agro-pastoralist societies interacted among themselves and with their neighbors in complex and dynamic environments.

In this paper we described the structure and some of the dynamics of the HouseholdsWorld model, including fluctuations in household wealth, camp sizes, and other simulation outputs. The MASON HouseholdsWorld model is being used for conducting experiments on socio-environmental interactions and social dynamics, as well as for developing additional models that reach higher levels of social complexity (state-formation).

Acknowledgments. An earlier version of this paper was presented at the 2nd World Congress on Social Simulation, George Mason University, Fairfax, Virginia, USA, 14-17 July, 2008. Funding for this study was provided by grant no. BCS-0527471 from the US National Science Foundation, Human and Social Dynamics Program, and by the Center for Social Complexity at George Mason University. The authors thank all members of the Mason-Smithsonian Joint Project on Inner Asia, especially Bill Honeychurch, Sean Luke, Bruno Frohlich, Bill Fitzhugh, Max Tsvetovat, and Dawn Parker, as well as three anonymous referees, and D. Tseveendorj of the Mongolian Academy of Sciences, Institute of Archaeology, Ulaanbaatar, Mongolia, for comments and discussions.

\section{References}

1. Arrow, H., McGrath, J. E., Berdahl. J. L. Small Groups as Complex Systems. Sage Publications, Thousand Oaks, London, and New Dehli, (2000)

2. Bah, A., I. Toure. An agent-based model to understand the multiple uses of land and resources around drillings in the Sahel, Mathematical and Computer Modelling 44, 513-534 (2006)

3. Berman, M, C. Nicholson, G. Kofinas, J. Tetlichi, S. Martin. Adaptation and sustainability in a small Arctic community: Results of an agent-based simulation model, Arctic 57, 401414 (2004)

4. Christian, D. A History of Russia, Central Asia and Mongolia, Blackwell, Oxford, UK, (1998)

5. Cioffi-Revilla, C. On the methodology of complex social simulations. Journal of Artificial Societies and Social Simulation 13: forthcoming (2010)

6..Cioffi-Revilla, C. Simplicity and Reality in Computational Modeling of Politics. Computational and Mathematical Organization Theory 15 (1):26-46 (2009)

7. Cioffi-Revilla, C. S. Paus, S. Luke, J. L. Olds, J. Thomas. Mnemonic Structure and Sociality: A Computational Agent-Based Simulation Model. In D. Sallach, C. Macal, eds., Proceedings of the Agent 2004 Conference on Social Dynamics: Interaction, Reflexivity and Emergence. Chicago, Argonne National Laboratory and University of Chicago (2004)

8. Cioffi-Revilla, C., S. Paus, S. Luke, J. L. Olds, and J. Thomas. Mnemonic Structure and Sociality: A Computational Agent-Based Simulation Model. In Proceedings of the Agent 2004 Conference on Social Dynamics: Interaction, Reflexivity and Emergence, edited by D. Sallach and C. Macal. Chicago, IL: Argonne National Laboratory and University of Chicago (2004b) 
9. Cioffi-Revilla, C., S. Luke, D. C. Parker, J. D. Rogers, W. W. Fitzhugh, W. Honeychurch, B. Frohlich, P. DePriest, and C. Amartuvshin. Agent-based Modeling Simulation of Social Adaptation and Long-Term Change in Inner Asia. In S. Takahashi, D. Sallach, J. Rouchier, Eds., Advancing Social Simulation: The First World Congress. New York and Tokyo, Springer (2007)

10.Cioffi-Revilla, C. W. Honeychurch, M. M. Latek, and M. Tsvetovat. The MASON Hierarchies model of political organization and warfare: Paper of record. Technical report, Mason-Smithsonian Joint NSF/HSD Project on Inner Asia, May 2008.

11.Epstein, J.M. Generative Social Science: Studies in Agent-Based Computational Modeling. Princeton, NJ: Princeton University Press (2007)

12. Grousset, R. The Empire of the Steppes: A History of Central Asia. Rutgers University Press, New Brunswick, NJ and London (1970)

13. Hildinger, E. Warriors of the Steppe: A Military History of Central Asia, 500 B.C. to 1700 A.D. Da Capo Press, Cambridge, MA (1997)

14. Kawamura, K., T. Akiyama, and H. Yokota. Comparing modis vegetation indices with avhrr ndvi for monitoring the forage quantity and quality in Inner Mongolia grassland and China. Japanese Society of Grassland Science (2004).

15. Khazanov. A.M., Nomads of the Eurasian steppes in historical retrospective. In L.E. Grinin, R.L. Carneiro, D.M. Bondarenko, N.N. Kradin, and A.V. Korotayev, Eds., The Early State, Its Alternatives and Analogues, pages 476-500, Uchitel Publishing House, Volgograd, Russia (2004)

16. Kohler, T.A., S. van der Leeuw. Model-Based Archaeology of Socionatural Systems. Santa Fe, NM, School of American Research (SAR) Press (2007)

17. Krader, L. Ecology of Central Asian Pastoralism. Southwestern Journal of Anthropology $11,301-326,(1955)$

18. Kuznar, L.A., R. Sedlmeyer. Collective violence in Darfur: An agent-based model of pastoral nomad/sedentary peasant interaction. Mathematical Anthropology and Culture Theory 1 (2005), available at: http://www.mathematicalanthropology.org/pdf/KuznarSedlmeyer1005.pdf

19. Luke, S., C. Cioffi-Revilla, L. Panait, K. Sullivan, Gabriel C. Balan. MASON: A Multiagent Simulation Environment. Simulation 81, 517-525 (2005), available at: http://cs.gmu.edu/ eclab/projects/mason/

20. Luke, S., L. Panait, G. Balan, S. Paus, Z. Skolicki, E. Popovici, K. Sullivan, J. Harrison, J. Bassett, R. Hubley, and A. Chircop. ECJ 18: A Java-based Evolutionary Computation Research System (2009), available at: http://www.cs.gmu.edu/ eclab/projects/ecj/

21. Milner-Gulland, E.J., C. Kerven, R. Behnke, I.A. Wright, A. Smailov. A multi-agent system model of pastoralist behaviour in Kazakhstan. Ecological Complexity 3, 23-36 (2006)

22. Rogers, J.D. The Contingences of State Formation in Eastern Inner Asia. Asian Perspectives 46, 249-274 (2007)

23. Rogers, J.D. C. Cioffi-Revilla. Expanding empires and the analysis of change. In E. Pohl, Ed., Mongolian Archaeology. Bonn University Press, Bonn, Germany (Forthcoming)

24. Rogers, J. D., M. Latek, T. Nichols, and T. Emmerich. 2009. Weather, Scale, and Complexity in Inner Asian Pastoralist Adaptive Strategies. Working Paper. Washington, DC: Mason-Smithsonian Joint Project on Inner Asia.

25. Rouchier, J., F. Bousquet. A multi-agent model for transhumance in North Cameroon. Journal of Economic Dynamics and Control 25, 527-559 (2001)

26. Watson, B., Ed. Records of the Grand Historian of China. Columbia University Press, New York (1961) 